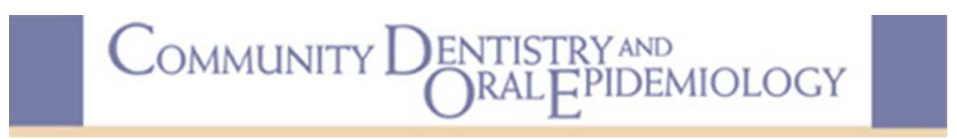

\title{
The impact of education on dental health - ways to measure causal effects
}

\begin{tabular}{|r|l|}
\hline Journal: & Community Dentistry and Oral Epidemiology \\
\hline Manuscript ID & CDOE-16-502.R2 \\
\hline Manuscript Type: & Commentary \\
\hline Complete List of Authors: & Grytten, Jostein; University of Oslo, Institute of Community Dentistry \\
\hline Keywords: & $\begin{array}{l}\text { Dental Health, Education, Twin studies, Regression discontinuity, } \\
\text { Instrumental variables }\end{array}$ \\
\hline Abstract: & $\begin{array}{l}\text { To our knowledge, there are no studies in which a possible causal effect of } \\
\text { education on dental health has been examined. Such studies are needed in } \\
\text { order to predict whether more schooling for people with poor dental health, } \\
\text { improves their dental health. Within social science, and in economics in } \\
\text { particular, several methods have been developed to make causal } \\
\text { inferences of the relationship between education and general health. These } \\
\text { methods, which are based on observational data, are relevant to use for } \\
\text { estimating a possible causal effect of education on dental health. This } \\
\text { commentary provides an overview of the state-of-the-art of the following } \\
\text { methods: the use of instrumental variables, twin studies and a regression } \\
\text { discontinuity design. By using these methods, reversed causality and the } \\
\text { omission of a third variable that influences both education and dental } \\
\text { health can be controlled for. In that way, an unbiased estimate of the } \\
\text { effect of education on dental health can be obtained. In order to implement } \\
\text { each of the methods correctly, several criteria have to be fulfilled. These } \\
\text { criteria are outlined and discussed below. }\end{array}$ \\
\hline
\end{tabular}




\title{
The impact of education on dental health - ways to measure causal effects
}

\author{
Jostein Grytten \\ Department of Community Dentistry, \\ University of Oslo
}

Corresponding author:

Jostein Grytten

Department of Community Dentistry, University of Oslo

Post Box 1052, Blindern

0316 Oslo, Norway

E-mail: josteing@odont.uio.no

Telephone: +4722840387 


\begin{abstract}
To our knowledge, there are no studies in which a possible causal effect of education on dental health has been examined. Such studies are needed in order to predict whether more schooling for people with poor dental health, improves their dental health. Within social science, and in economics in particular, several methods have been developed to make causal inferences of the relationship between education and general health. These methods, which are based on observational data, are relevant to use for estimating a possible causal effect of education on dental health. This commentary provides an overview of the state-ofthe-art of the following methods: the use of instrumental variables, twin studies and a regression discontinuity design. By using these methods, reversed causality and the omission of a third variable that influences both education and dental health are can be controlled for. In that way, an unbiased estimate of the effect of education on dental health can be obtained. In order to implement each of the methods correctly, several criteria have to be fulfilled. These criteria are outlined and discussed below.
\end{abstract}

Key words: education, dental health, causal estimates, instrumental variables, twin studies, regression discontinuity

Running title: a possible causal effect of education on dental health 


\section{Introduction}

One of the most robust findings in the dental literature is the positive association between education and dental health. This relationship is found in many countries, at different educational levels and for various indicators of dental health. In a broader sense, the positive association between education and health is so ubiquitous that it is often referred to as "the gradient" $"$ "- However, this association may not reflect a causal relationship.

To my knowledge, there is a lack of studies in which a possible causal effect of education on dental health has been examined. Although correlation studies have a role to play, I believe that the most interesting research is about cause and effect. This is because causal estimates can be used to make valid predictions about the consequences of a change in circumstances or policies. For example, does more schooling for people with poor dental health, improve their dental health?

During the last 5-10 years, within the economic literature, there has been a lively debate about whether the relationship between education and health is causal or not (for example see: $\left.{ }^{5-8}\right)$. Alternatively, how much of it is causal? In this commentary, I will refer to this discussion, and relate it to the field of dentistry. Within the economic literature, a broad range of methods have been adopted for the estimation of causal effects. These methods are relevant to use for the estimation of causal effects of education on dental health. The strengths and weaknesses of these methods are discussed below. I will discuss the effects of formal education only. Use of non-formal education, such as the use of Google and Wikipedia as an easy and useful source of general and specific knowledge to solve problems is not discussed.

\section{Education - an important policy instrument}

This discussion about causal effects of education on dental health is highly relevant for policy because, certainly in the long run, education is amenable to public policy interventions. For example, during the second half of the last century there has been a 
remarkable increase in the level of education in most western European countries ${ }^{9-14}$. In 1960 only $5 \%$ of the population aged 25-64 years had tertiary education (Fig. 1). This figure is the average for 14 western European countries. In 2005 the proportion had increased to nearly $30 \%$. To a large extent, this increase is the result of public policies, which have led to a substantial increase in the number of colleges and universities. Demand side policies have also been effective, such as student grants and loans to stimulate young adults to continue their education to a higher level.

It is commonly believed that more schooling has given pecuniary returns, both to the individual and to society as a whole. At the individual level more schooling leads to an increase in labour participation and to higher earnings ${ }^{15}$. At the more aggregate level, an increase in the proportion of young adults with tertiary education has made a substantial contribution to the economic growth seen in most western countries during the second half of the last century ${ }^{16}$. The issue is to what extent more schooling also provides nonpecuniary returns, such as happier marriages, better parenting, more stable social networks, more trustworthy individuals and better general health, dental health included. Better health is often singled out as the key non-pecuniary benefit from additional schooling ${ }^{17}$.

From a policy and efficiency point of view, it is a great advantage if education leads to an increase in both pecuniary and non-pecuniary benefits. By using one policy instrument only, i.e. raising the level of education, governments can achieve two aims simultaneously: raise the wealth of the population and improve health. In the long run, this would be a more successful policy than focusing on policies that only aim to improve health, such as increasing public health care expenditure. In fact, such policies may not be that effective. More resources spent on curative health care may have a minor effect on the health of the population $^{18-21}$. 


\section{What does schooling do?}

Within a broader context, and depending on the region/country, schooling serves several aims, such as ${ }^{22-24}$ :

- to develop personal autonomy and development of knowledge, skills and attitudes so that pupils can master their lives and as adults take part in working life and society

- $\quad$ to promote values related to democracy, equality and solidarity

- $\quad$ to teach pupils to act ethically and to respect human dignity and intellectual freedom.

With respect to the possible effect that schooling may have on health, the development of skills is particularly important. There are at least three types of skills ${ }^{25}$ :

- Knowledge-based skills:

Students learn to use information to develop skills that are needed to perform specific tasks.

- Critical thinking skills:

Students learn logical reasoning so that they are able to assess information and draw inferences or conclusions that are supported by evidence.

- Social skills:

These skills facilitate interaction and communication with others, such as interaction with authorities and social structures/systems.

The key question is then: Do the skills acquired through schooling lead to better dental health? A plausible answer is "yes". In that case, the positive association between education and dental health should be interpreted as causal. This association could then be estimated using ordinary least squares regression analysis. However, there are other factors that can cause a positive association that have to be controlled for, i.e. eliminated from the picture. These factors are reversed causality and the omission of a third variable that influences both education and dental health ${ }^{6,26}$. Unless reversed causality and the third variable are 
controlled for, the regression coefficients measuring the effect of education on dental health are likely to be biased, i.e. the causal effect will be overestimated.

\section{Reversed causality}

The direction of causality may run from better health to more education. In that case, health status contributes to the individual's social status. Within the literature in epidemiology and sociology, this is commonly termed a selection effect or a social drift effect ${ }^{27,28}$. These effects are most likely for diseases with an early onset that affect adult health. According to Grossman and Kaestner (1997) the observed relationship between adult health and schooling most likely suffers from an omitted variable bias unless infant/child health is controlled for in the analyses ${ }^{26}$. The omitted variable (infant/child health) is positively correlated with both adult health and schooling. Therefore, the omitted variable bias will be upwards $^{26}$. Currie (2009) and Eide and Showalter (2011) have given excellent reviews of the literature that deals with the effects that infant/child health has on adult health and on education $^{29,30}$. There are several pathways in which these effects may run - a few pathways are given below.

First, it is well established that infants with low birth weight have poorer school outcomes than infants with normal birthweight ${ }^{31-38}$. In addition, low birth weight is associated with poor health later in life; such as high blood pressure, cardiovascular disease, diabetes, asthma, kidney disease, mental disorders and caries ${ }^{39-45}$. Several of these health conditions are risk factors for reduced life expectancy.

Second, children's and adolescents' mental health has recently been recognized as being important for future life outcomes. For example, adolescents with behaviour problems such as hyperactivity and conduct disorders have significantly less schooling, lower earnings and less employment ${ }^{46-49}$. Teenagers diagnosed with ADHD have lower cognitive test scores than other children for mathematics and reading, much higher probabilities of being in special education or having repeated a year at school, and more 
likely to suffer recurrent mental health problems as adults ${ }^{50-53}$. These effects are larger for ADHD than for other mental health problems, such as depression, among teenagers ${ }^{51}$. Mental health symptoms that are not a diagnosis, such as mood changes and sleeping problems, may also be important for teenagers' performance at school.

Third, older children who are sick or malnourished during childhood, independent of their birthweight, are more likely to miss school, learn less, and ultimately obtain fewer years of schooling ${ }^{26}$. Sick children are also more likely to become sick as adults. Specific diseases among children and adolescents that have been identified as being important for future educational attainment and adult health are: migraine, asthma and infectious diseases such as typhoid, measles, influenza and diarrhea ${ }^{54-57}$.

\section{Omission of a third variable}

Third variables influencing both education and health will lead to a biased estimate of the causal effect of education on health. In the case that the omitted variables are positively correlated with both education and health, the estimate will be upward biased. Third variables often mentioned in the literature are: parent's and sibling's level of education, cognitive ability, place of residence, and characteristics of the spouse 6,17,26 $^{\text {(Fig. 2). }}$

Evidence from both the economic literature, and from the non-economic literature such as psychology, sociology and epidemiology, has shown that wealthy parents are likely to invest more in their children's health and in their education than less wealthy parents ${ }^{7,58-63}$. Therefore, unless family characteristics are controlled for, the regression coefficient measuring the effect of education on dental health is likely to be biased. Ability is another important confounding variable that should be controlled for. Smarter individuals may be more likely to obtain more schooling and to take better care of themselves, for example by having more favourable health behaviour ${ }^{64,65}$. Another potential confounder is place of residence ${ }^{66,67}$. For example, highly educated and wealthy individuals tend to live in affluent areas. These are also areas where the quality of both schooling and medical services is likely to be high. Finally, characteristics of the spouse may be an important confounder. A 
highly educated person may marry a person who is also highly educated, and who has favourable health behaviour. Spillover effects with respect to adapting each other's health behaviour are likely ${ }^{68-72}$.

In the economic literature, the third variable most often mentioned is time preference ${ }^{73,74}$ (Fig. 2). Decisions about education and health involve trade-offs of different outcomes over time. How does the individual trade off current outcomes over future outcomes? People with a strong preference for the future relative to the present are more likely to invest in education, and at the same time they are more likely to engage in healthier activities and habits. Conversely, people who value the present highly will invest less in both education and healthy activities, such as looking after their teeth. It then follows that time preferences are likely to be positively correlated with both education and health. Unless these preferences are controlled for, the regression coefficients measuring the effect of education on health are likely to be upward biased, i.e. the causal effect will be overestimated ${ }^{75}$. Therefore, time preferences must be controlled for.

As early as 1982, the award winning health economist Victor Fuchs rejected the hypothesis that education has a causal effect on smoking ${ }^{73,74}$. He showed that a negative relationship between education and smoking was due to time preferences. Time preferences represent the individual's preference for current outcomes over future outcomes, i.e. preferences over the timing of outcomes ${ }^{75}$. The time preference hypothesis has been tested by several researchers during the decades that followed after Fuchs's work. The main conclusion from that research is that the effect of education on health is markedly reduced, but does not disappear when time preferences are controlled for ${ }^{75,76}$.

\section{The instrumental variable approach}

It is hard to distinguish a possible causal effect of education on dental health from potential confounders. One possibility is to make a list of all the confounders one can think of, and 
include them in a regression model with education as the key explanatory variable and dental health as the outcome. This approach is difficult, mainly because several confounders are difficult to identify and measure. For example, how do you get a valid measure of ability? Even if the confounders could be measured, they may not be available in the set of data, or they may have been measured imprecisely.

Even if a possible confounder is available in the set of data, it should not necessarily be included in the analyses. This is supported by the evidence from research within the field of directed acyclic graphs ${ }^{77,78}$. The so-called colliders are of special interest. A variable is classified as a collider when it is the outcome of two variables of interest, for example an exposure and an outcome. Controlling for a collider will cause the regression coefficient between the exposure and the outcome to be biased. This is because controlling for the collider opens the path between the exposure and the outcome, introducing a spurious (non-causal) association. the collider introduces a spurious (non-causal) association between the exposure and the outcome. In technical terms, the collider "blocks" the association between the two variables of interest ${ }^{77,78}$.

Both unobserved variables and colliders are a challenge, because they easily introduce bias in the estimates of causal effects. To correct for these biases, several statistical techniques have been developed ${ }^{79}$. In econometrics, probably the most commonly used technique is the use of instrumental variables ${ }^{80,81}$. Within dental public health and dentistry in particular, instrumental variables have hardly been used. Instrumental variables began to be used in econometrics a long time ago. A substantial amount of work has subsequently been done to develop methods using these variables within epidemiology ${ }^{81-84}$. One can think of an instrumental variable as a device in which pseudo randomization is achieved using observational data. In an experiment, the assignment of individuals to a control group and a treatment group is done by randomization; i.e. they are not allocated to a group according to factors that are correlated with the outcome. Instrumental variables are like a natural experiment. With the use of instrumental variables, the idea is to mimic the random assignment of controlled experiments by taking advantage of incidents where nature (for example floods, hurricane) or institutional rules and designs (for example 
introduction of any health care strategy, educational reforms) give rise to random variation $^{79}$. It exploits the fact that nature sometimes makes random assignments. Therefore, such strategies for identification are often referred to as natural or quasiexperiments $^{85-87}$.

Within epidemiology and social sciences randomized controlled experiments are seldom feasible $^{88}$. It would be unethical, practically difficult and very costly to randomly allocate preschool children into a "treatment group" and a "control group". The treatment in this case is higher education, and the control group is compulsory schooling only.

Ideally, one would also want to observe the same child both as a control subject and as a test subject. This is not possible. The key issue is then to estimate what would have happened in the counterfactual situation; i.e. which outcome a treated person would have if he or she had not been treated. Differences in outcomes would then be fully explained by differences in length of schooling. As the counterfactual situation is not possible to observe, statistical techniques and research designs have been developed that have helped researchers to come as close as possible to this counterfactual comparison. Use of instrumental variables is one such technique, which if certain assumptions are fulfilled, is an effective tool to obtain causal estimates ${ }^{89}$ (Fig. 3).

These assumptions are ${ }^{90}$ :

First, the instrumental variable must have a clear effect on the treatment variable; in our case on educational level. This is usually termed "instrument relevance".

Second, the instrumental variable must not be correlated with the error term in the first stage regression, i.e. where the treatment variable is regressed on the instrumental variable. Alternatively, for a strong instrument this correlation can be small ${ }^{90}$.

Third, the instrumental variable must not be correlated with the error term in the regression equation. This is usually termed "the exclusion restriction". This means that the instrumental variable has an effect on the outcome only through the treatment variable. In 
that case, biases caused by reversed causality and omission of a third variable are eliminated.

\section{One type of instrument - school reforms}

The trick is then to find a convincing instrumental variable. Valid instrumental variables are developed from a combination of in-depth institutional knowledge of the sector under study, and insight into the mechanism that determines the relationship between the instrumental variable and the treatment variable ${ }^{89}$. So far, within the social science literature, the most promising type of instrumental variable has been the introduction of compulsory schooling laws ${ }^{91}$. Such laws were introduced in several European and North American countries in different time periods during the last century.

Typically, one of the most prominent the effects of these laws was that the number of years of compulsory schooling was increased. In several countries, the number of years of compulsory schooling was increased from 7 to 9 years during the $1960 \mathrm{~s}$ and the $1970 \mathrm{~s}^{92}$. The laws were implemented at a national level and encompassed all preschool children; i.e. there was no selection of preschool children to the treatment group or control group according to their abilities, or their parents' level of education. The "treatment" group was then comprised of children with 9 years of compulsory education, and the "control" group was comprised of children with 7 years of compulsory education.

Several economists have used the random variation induced by the introduction of compulsory schooling to estimate causal effects of education on different types of health outcome measures (for example see: ${ }^{93-101}$ ). Such studies have been performed in the United States, Great Britain, the Netherlands and the Scandinavian countries. In several of the studies, but not all of them, a causal effect of education has been found. Typically, the regression coefficient from the instrumental variable estimation is smaller, often much smaller, than the ordinary least squares estimation (for a review see: ${ }^{91,92}$ ). This underscores the importance of using a statistical technique in which confounding variables have been 
controlled for. These confounding variables are unobservable, hence their individual effects cannot be estimated.

Several studies have found that the causal effects vary by gender ${ }^{95,100,102-104}$. For example, in a study from Germany, Kemptner et al. (2011) used the random variation induced by a school reform to estimate causal effects of education on different types of health outcome measures separately for men and women ${ }^{100}$. In Germany, the number of years of compulsory schooling increased from 8 to 9 years during the period 1949 to 1970. Kemptner et al. (2011) showed in the first stage regression that the introduction of a compulsory $9^{\text {th }}$ grade led to an increase in schooling of 0.6 years ${ }^{100}$. This is equivalent to the effect shown by the arrow from the instrumental variable to the treatment variable in Fig. 3. For men, the second stage estimate showed that one more year of schooling led to a reduction in the likelihood of work disability of 3.2 percentage points, and of suffering from a long term illness of 4.1 percentage points. These figures are equivalent to the effect shown by the arrow from the treatment variable to the outcome variable in Fig. 3. In contrast to men, women did not gain from more schooling in terms of improvements in health: the second stage estimate had an insignificant effect on health outcomes.

Typically, all most studies in which a school reform has been used as an instrumental variable have been performed using panel data. Use of panel data is a great advantage, as it makes it possible to perform an anti-test (placebo test) ${ }^{105}$. Such a test can be used to assess the validity of the instrumental variable. An anti-test provides counter evidence by estimating a model in a context where no effect should be found. If an apparent effect is found, then the validity of the instrumental variable is questionable ${ }^{105}$.

With panel data we can test the assumptions of instrumental variable estimation by pretending perform an experiment in which we pretend that the increase in the number of years of compulsory schooling was introduced earlier than it actually was introduced. In such an experiment, we do not expect the reform to have any effect on health outcomes. If 
there is an effect, the instrumental variable would be correlated with a third variable. Then we have a poor instrument.

\section{Weaknesses of the instrumental variable approach}

In the literature, different types of instrumental variables have been suggested. Most of them, but not all, have been dismissed (for a review see: ${ }^{6}$ ). The main reason is that the instrumental variable does not have a clear effect on the treatment variable. The correlation between the instrumental variable and the treatment variable might be small, i.e. the instrument is weak. This will occur with confounding ${ }^{90}$. Generally, the correlation between the instrumental variable and the treatment variable becomes weaker as the amount of confounding becomes larger. A weak instrumental variable leads to a biased estimate of the treatment effect. This bias will be in the direction of the estimate from the ordinary least squares regression of the outcome on the treatment variable ${ }^{90}$. Information about the size of the bias can be obtained from the F-statistic, where the treatment variable is regressed on the instrumental variable (i.e. the first stage regression). An F-value close to 1 indicates a large sample bias, whereas a value of 10 indicates that the bias is negligible ${ }^{106}$. A strength of most studies in which the introduction of a school reform has been used as an instrumental variable is that the F-values have been high $^{95-97,99-101,107}$.

A potential weakness of using compulsory schooling laws for identification is that the consistency assumption for causal inference may be violated. This assumption "entails that the exposure is defined with enough specificity that different variants of the exposure do not have different effects on the outcome"108 . Commonly, education is operationalized as the number of years of compulsory schooling. This measure does not capture different aspects of school quality; such as differences in school term duration. Another factor to consider is that compulsory schooling laws either introduce an extra year of schooling at an early age (for example the school entry age is reduced from 7 to 6 years of age) or an extra year of schooling in adolescence (for example the school leaving age is increased from 14 to 15 or 16 years of age). Young and old children are at different stage of development. 
This is not taken into account in the instrumental variable estimation, where the number of years of schooling is the treatment variable. Rehkopf et al. (2016) argue that "multiple attributes of education that are not typically specified may be differently associated with health outcomes, thus use of standard measures of level of education may violate the consistency assumption" ${ }^{\prime 108}$. In that case, the instrumental variable does not give a valid estimate of the causal effects of education on health outcomes. This has led researchers to look for alternative methods to estimate causal effects. Two such methods are twin studies, and studies with a regression discontinuity design.

\section{Twin studies}

Identical (monozygotic) twins share common genes and have a common family background. Therefore, at the end of the last century, twin studies were considered to be a very promising way of estimating the causal effects of education on health outcome ${ }^{17,91}$. It was commonly believed that confounding variables related to intelligence and family characteristics were controlled for with samples of identical twins.

However, there are few identical twin studies in which the effect of education on health outcomes has been examined. In the few studies that exist, the effect of education is smaller in twin studies than in studies of the general population ${ }^{109-111}$. This indicates that intelligence and family characteristics are important confounding variables.

One challenge when studying identical twins is to get a large enough sample. A larger sample can be obtained by including non-identical (dizygotic) twins in the samples. That improves the statistical power of the analyses. Dizygotic twins are expected to share the same family environment, but their genes are different. However, it can be questioned whether the family environment is similar for both twins. For example, twins that are not of same sex may be treated differently by parents, teachers and society in general.

An interesting approach is would be to compare the similarity in health outcomes according to schooling of identical and non-identical twins. Such a comparison could provide insight 
into the role of genes as opposed to family characteristics in determining education and health outcomes ${ }^{109,110,112}$. For example, we might find an effect of education on health outcomes for non-identical twins, but not for identical twins. That would indicate that genetics is the confounding variable that determines both level of education and health.

An extension of non-identical twin studies is comparison between siblings and between cousins. This is frequently done in epidemiology, public health and psychology ${ }^{78,113-116}$. In studies with a sibling-comparison design, the researcher exploits the fact that siblings share the same family environment as well as half the genome ${ }^{78,117}$. Outcomes are compared between siblings who are discordant on the intervention, and who are as similar as possible in family context and genetic predisposition. To my knowledge, There are no a few studies in which a sibling-comparison design has been used to estimate the causal effects of education on health outcome $e^{118,119}$. Such a design is not without its limitations. A concern is that the design is sensitive to measurement error and to confounding from factors that the siblings do not share ${ }^{116,117,120}$. Further, there should be no carryover effects; i.e. the effect of each participant's exposure to the risk factor should not influence the unexposed participants ${ }^{116,117,120}$. This assumption may be difficult to fulfill in the case where the exposed sibling and the unexposed sibling vary in years of schooling only. Skills and knowledge may well be transferred from the sibling with the most schooling to the sibling with the least schooling. The effect of schooling may then be underestimated.

Recently, several shortcomings of identical twin studies have also been suggested ${ }^{112,121}$. Are differences in schooling between identical twins random? Since monozygotic twins are meant to be genetically identical, it has been assumed that any variation in their schooling must be purely random. This may not be the case.

Monozygotic twins are different because they have different experiences. Different experiences begin as early as in the womb. For example, they compete for nourishment in the uterus. The "winner" grows and thrives at the expense of the "loser". The result is a difference in birthweight, which is correlated with a difference in educational attainment, ability and health later in life ${ }^{34,122-124}$. After birth, twins continue to experience different 
environments. For example, they may be separated when they start school by being placed in different classes, then they are exposed to different teachers and classmates. Parents do not treat identical twins the same; a less able twin may be treated differently from a more able twin. Also, identical twins have different personalities, and this also causes parents to treat them differently. Finally, from an early age twins have a psychological need to be individuals. This increases their differences.

This indicates that differences in schooling between identical twins may be systematic rather than random. If these systematic differences are correlated with both education and health, then identical twin studies are not likely to provide causal estimates of education on health.

\section{Regression discontinuity design}

Regression discontinuity uses precise rules that determine whether an individual ends up in a treatment group or a control group ${ }^{125}$. The designs are of two types: sharp design and fuzzy design. A graphical illustration of the sharp design is given in Fig. 4. All individuals who score above a predetermined cut-off value are assigned to the intervention group (treatment group), while those who score below are assigned to the control group. This is different from in a randomized controlled trial in which individuals are randomly assigned to a treatment group or a control group. In this simple illustration, the difference or "discontinuity" in the two regression lines provides an estimate of the intervention effect.

The idea of the regression discontinuity design is to compare individuals in a small range above and below the cut-off point ${ }^{126,127}$. These individuals only differ by being treated or not treated. They are meant to be identical regarding all observable and unobservable confounding variables that could influence the outcome. Any difference in outcome around the cut-off value can then be interpreted as a causal effect of the intervention. A limitation of the regression discontinuity design is that the external validity is often low. The results are difficult to generalize to populations within a broader range from the cut-off value. 
An example of a cut-off value commonly used is date of birth, for example the $1 \mathrm{st}$ January $^{128,129}$. In several countries, school start is determined by the calendar year in which children are born. Children who were born in December are the youngest, and those who were born in January are the oldest in their class. Typically, researchers use this difference in date of birth around the cut-off value to examine the effects of age at school entry on outcomes such as test scores, educational attainment and labour market participation (for a review see: $\left.{ }^{130}\right)$. The question is whether children who start school at a younger age do worse than those who start at an older age.

In a few studies, a fuzzy regression discontinuity design has been used to estimate the causal effects of education on health outcomes ${ }^{94,95,131}$. In such a design, treatment and control individuals are observed both below and above the cut-off point. The design exploits discontinuities in the probability of treatment. Thus, it can be interpreted as an instrumental variable approach where the discontinuity is the instrument for treatment $^{79}$. Van Kippersluis et al. (2011) used the discontinuity in schooling caused by a school reform in the Netherlands in the $1920 \mathrm{~s}$, to estimate causal effects of education on mortality in old age $\mathrm{e}^{95}$. The first stage regression showed that the years of schooling increased by 0.8 years around the cut-off point. Their second stage estimate showed that one more year of schooling reduced the probability of dying before the age of 89 by 3 percentage points. Van Kippersluis (2011) performed several robustness tests, which showed that the treatment was as good as randomly assigned around the cut-off point ${ }^{95}$.

\section{Issues related to statistical inference}

All the three methods described above rely on the use of regression analyses for estimation. In order to obtain reliable estimates from the analyses, there are at least three statistical issues to consider. These are: 
First, clustering: Typically, the data will have a multilevel structure, for example preschool children living in different municipalities, and twins growing up in different families. In statistical terms, individuals are clustered within a higher order unit. Observations within a cluster are correlated - there is dependence between them. This is because preschool children or twins within the same cluster have some of the same environmental and family background characteristics. Failure to control for within-cluster dependence can lead to misleadingly small standard errors, and consequently low p-values, i.e. the null hypothesis will incorrectly be rejected ${ }^{132}$. Controlling for clustering within data by using clustered/robust standard errors is fairly straightforward with cross-sectional data, but a bit trickier with panel data. With panel data, there is correlation between the same observations over time as well as correlation between different observations at one point in time. The correlation over time is due to the fact that, for example, once a school reform has been implemented it remains in place in all the subsequent years. With panel data, controlling for clustering within data by using clustered/robust standard errors can be particularly challenging in the case of "few" clusters, usually defined as less than $20^{132}$.

Second, trends: With panel data, it is common to include different trend specifications in the regression analyses. This is particularly important if unobserved variables influence the treatment group and the control group differently ${ }^{133}$. Whether this is the case or not, can be tested. For example, in the analyses using the introduction of compulsory schooling laws as the instrumental variable, municipality specific trends could be included as control variables. The estimate of schooling on mortality is biased if it is influenced by the inclusion of these trend variables. In that case, the instrumental variables are correlated with some unobservable variables in the error term in the regression equation. Then the exclusion criterion for the instrumental variable is violated and the instrument is most likely not appropriate for examination of the effect, which may still be causal.

Third, external validity: For several identification strategies, only part of the population is exposed to the intervention. For example, the introduction of compulsory schooling laws only affects those at the bottom tail of the educational distribution. The 
question is whether we can generalize the findings to people in the middle and upper range of the educational distribution ${ }^{89,134}$. For twin samples, the question is whether the findings can be generalized to the population of people who are not twins. Under certain assumptions such a generalization is possible. These assumptions are outlined and discussed in the broader and more recent literature related to local and average treatment effects $^{89,134}$.

\section{Issues related to interpretation of causal estimates}

A relevant question is whether the causal estimate obtained through the use of compulsory schooling laws, should be interpreted as an absolute or a relative effect of education. In the case of an absolute effect interpretation, the focus is on each individual's level of education, and whether more schooling lowers the risk of mortality or having poor health. An alternative view is that an individual's health is also a function of the level of education in his or her reference group. Usually, the relevant reference group is defined as individuals who live in the same area, for example in the same municipality ${ }^{135-139}$. Relative education can then be defined as the level of education of an individual relative to the mean educational level of the reference group. The causal estimates of education on health identified through compulsory schooling laws may represent a relative rather than an absolute effect. This is because a school reform functions as a way of stratifying individuals relative to each other. Those who were exposed to the reform increase their level of education relative to those who were not exposed. This implies that those who were exposed benefit, in terms of better health, while those who were not exposed may lose out in terms of worse health.

In the literature in public health and epidemiology, there are numerous studies in which the effects of relative income on health have been estimated. In several studies, it is found that relative income matters (for a review see: ${ }^{140-143}$ ). Wilkinson has argued that this is because people are concerned about their place in the social hierarchy, based on their relative position according to income ${ }^{144}$. Low relative income may cause psychosocial stress and 
depression, conditions that are associated with poor health and risky health behaviour such as smoking and drinking. Lynch et al. (2000) further argue that a low place in the hierarchy can easily be translated into "antisocial behaviour, reduced civic participation, and less social capital and cohesion within the community" ${ }^{\prime 45}$. These are all factors that raise the probability of contracting an illness. These effects of relative income are most likely caused by education $^{146,147}$. In real life, education predates income, and those with more education have higher income. Thus income may be the mediating variable in which education exerts its effect. Most likely, in the case of identification through compulsory schooling laws, this effect is due to a relative effect of education.

\section{Conclusion}

There are different strategies that can be used to estimate causal effects of education on dental health. They each have their strengths and weaknesses. Identification through compulsory schooling laws is a promising strategy. This is because in most studies, the instrument has been shown to be valid; as indicated by high F-values. A potential weakness using compulsory schooling laws for identification is that the consistency assumption for causal inference may be violated. In particular, years of compulsory schooling does not capture different aspects of school quality. Identical twin studies have the potential to identify causal effects. The challenge is to get large enough samples, which is necessary in order to obtain sufficient precision of the regression coefficients. Larger samples can be obtained by using non-identical twins, siblings or cousins. However, such a design is not without its limitations. A particular concern is confounding from factors that the siblings do not share. The use of a regression discontinuity design is an alternative. However, the challenge is to find a precise rule to determine whether a child ends up in the group with much schooling (treatment group) or the group with little schooling (control group). It is not obvious what the rule should be.

Whatever the weaknesses are, the use of one or more of the methods outlined above is an improvement on the methodologies that have been used so far to estimate the relationship 
between education and dental health. The prevailing methods, which have been correlation studies, have not been able to provide causal estimates. The methods described above have the potential to provide such estimates.

\section{Acknowledgements}

I wish to thank Linda Grytten for language correction and Irene Skau for useful comments and technical assistance. 


\section{References}

1. Watt RG, Listl S, Peres M, Heilman A, editors. Social inequalities in oral health: from evidence to action. London: International Centre for Oral Health Inequalities Research \& Policy, 2015.

2. Sabbah W, Tsakos G, Chandola T, Sheiham A, Watt RG. Social gradients in oral and general health. J Dent Res 2007; 86: 992-6.

3. Geyer S, Schneller T, Micheelis W. Social gradients and cumulative effects of income and education on dental health in the Fourth German Oral Health Study. Community Dent Oral Epidemiol 2010; 38: 120-8.

4. Sanders A, Slade GD, Turrell G, Spencer AJ, Marcenes W. The shape of the socioeconomic-oral health gradient: implications for theoretical explanations. Community Dent Oral Epidemiol 2006; 34: 310-9.

5. Cutler DM, Lleras-Muney A. Education and health: evaluating theories and evidence. NBER Working Paper 12352. Cambridge, MA: National Bureau of Economic Research, 2006. Available at: http://www.nber.org/papers/w12352 (February 16, 2017).

6. Grossman M. Education and nonmarket outcomes. In: Hanushek EA, Welch F, editors: Handbook of the economics of education, Volume 1. North-Holland: Elsevier, 2006; 577-633.

7. Desai S, Alva S. Maternal education and child health: is there a strong causal relationship? Demography 1998; 35: 71-81.

8. Cutler DM, Lleras-Muney A, Vogl T. Socioeconomic status and health: dimensions and mechanisms. In: Glied S, Smith PC, editors: The Oxford handbook of health economics. Oxford: Oxford University Press, 2011; 124-63. 
9. Dolton P, Asplund R, Barth E. Education, wage inequality and the labour market. In: Dolton P, Asplund R, Barth E, editors: Education and inequality across Europe. Cheltenham: Edward Elgar, 2009; 1-23.

10. De la Fuente A, Doménech R. Educational attainment in the OECD, 1960-95. CEPR Discussion Paper No. 3390. London: Centre for Economic Policy Research, 2002.

11. OECD. Education at a glance 2005. Paris: OECD, 2005.

12. OECD. Education at a glance 2006. Paris: OECD, 2006.

13. OECD. Education at a glance 2007. Paris: OECD, 2007.

14. OECD. Employment outlook 2007. Paris: OECD, 2007.

15. Harmon C, Oosterbeek H, Walker I. The returns to education: microeconomics. J Econ Surv 2003; 17: 115-55.

16. Sianesi B, Van Reenen J. The returns to education: macroeconomics. J Econ Surv 2003; 17: 157-200.

17. Oreopoulos P, Salvanes KG. Priceless: the nonpecuniary benefits of schooling. J Econ Perspect 2011; 25: 159-84.

18. World Health Organization. The World Health Report 2000. Health systems: improving performance. Geneva: World Health Organization, 2000.

19. Evans RG, Barer ML, Marmor TR, editors. Why are some people healthy and others not? The determinants of health of populations. New York: Aldine de Gruyter, 1994.

20. Watt RG. From victim blaming to upstream action: tackling the social determinants of oral health inequalities. Community Dent Oral Epidemiol 2007; 35: 1-11. 
21. Petersen PE. The World Oral Health Report 2003: continuous improvement of oral health in the $21^{\text {st }}$ century - the approach of the WHO Global Oral Health Programme. Community Dent Oral Epidemiol 2003; 31 (Suppl 1): 3-24.

22. Brighouse H. Moral and political aims of education. In: Siegel H, editor: The Oxford handbook of philosophy of education. Oxford: Oxford University Press, 2009.

23. Child Rights International Network. Convention on the rights of the child. Article 29: aims of education. Available at:

https://www.crin.org/en/home/rights/convention/articles/article-29-aims-education . (February 16, 2017).

24. Ministry of Education and Research. Education act. 2007. Available at: https://www.regjeringen.no/en/dokumenter/education-act/id213315/ (February 16, 2017).

25. Embrey D. Understanding human behaviour and error. Human Reliability Associates, 2005. Available at: http://www.humanreliability.com/articles/ Understanding\%20Human\%20Behaviour\%20and\%20Error.pdf (February 16, 2017).

26. Grossman M, Kaestner R. Effects of education on health. In: Behrman JR, Stacey N, editors: The social benefits of education. Ann Arbor: The University of Michigan Press, 1997; 69-123.

27. Adler NE, Ostrove JM. Socioeconomic status and health: what we know and what we don’t. Ann NY Acad Sci 1999; 896: 3-15.

28. Fox AJ, Goldblatt PO, Jones DR. Social class mortality differentials: artefact, selection or life circumstances? J Epidemiol Community Health 1985; 39: 1-8.

29. Currie J. Healthy, wealthy, and wise: socioeconomics status, poor health in childhood, and human capital development. J Econ Lit 2009; 47: 87-122. 
30. Eide ER, Showalter MH. Estimating the relation between health and education: what do we know and what do we need to know? Econ Educ Rev 2011; 30: 778-91.

31. Bhutta AT, Cleves MA, Casey PH, Cradock MM, Anand KJS. Cognitive and behavioral outcomes of school-aged children who were born preterm. JAMA 2002; 288: 728-37.

32. Anderson P, Doyle LW, the Victorian Infant Collaborative Study Group. Neurobehavioral outcomes of school-age children born extremely low birth weight or very preterm in the 1990s. JAMA 2003; 289: 3264-72.

33. Hack M, Flannery DJ, Schluchter M, Cartar L, Borawski E, Klein N. Outcomes in young adulthood for very-low-birth-weight infants. N Engl J Med 2002; 346: 14957.

34. Black SE, Devereux PJ, Salvanes KG. From the cradle to the labor market? The effect of birth weight on adult outcomes. Q J Econ 2007; 122: 409-39.

35. Currie J, Hyson R. Is the impact of health shocks cushioned by socioeconomic status? The case of low birthweight. Am Econ Rev 1999; 89: 245-50.

36. Behrman JR, Rosenzweig MR. Returns to birthweight. Rev Econ Stat 2004; 86: 586-601.

37. Royer H. Separated at girth: estimating the long-run and intergenerational effects of birthweight using twins. Ann Arbor MI: Ford School of Public Policy, University of Michigan, 2005.

38. Conley D, Bennett NG. Is biology destiny? Birth weight and life chances. Am Sociol Rev 2000; 65: 458-67.

39. Hardy R, Wadsworth MEJ, Langenberg C, Kuh D. Birthweight, childhood growth, and blood pressure at 43 years in a British birth cohort. Int J Epidemiol 2004; 33: 121-9. 
40. Holland FJ, Stark O, Ades AE, Peckham CS. Birth weight and body mass index in childhood, adolescence, and adulthood as predictors of blood pressure at age 36. J Epidemiol Community Health 1993; 47: 432-5.

41. Hoy WE, Rees M, Kile E, Mathews JD, Wang Z. A new dimension to the Barker hypothesis: low birthweight and susceptibility to renal disease. Kidney Int 1999; 56: 1072-7.

42. Iliadou A, Cnattingius S, Lichtenstein P. Low birth weight and Type 2 diabetes: a study on 11162 Swedish twins. Int J Epidemiol 2004; 33: 948-53.

43. Shaheen SO, Sterne JAC, Montgomery SM, Azima H. Birth weight, body mass index and asthma in young adults. Thorax 1999; 54: 396-402.

44. Wahlbeck K, Forsén T, Osmond C, Barker DJP, Eriksson JG. Association of schizophrenia with low maternal body mass index, small size at birth, and thinness during childhood. Arch Gen Psychiatry 2001; 58: 48-52.

45. Nicolau B, Marcenes W, Bartley M, Sheiham A. A life course approach to assessing causes of dental caries experience: the relationship between biological, behavioural, socio-economic and psychological conditions and caries in adolescents. Caries Res 2003; 37: 319-26.

46. Miech RA, Caspi A, Moffitt TE, Entner Wright BR, Silva PA. Low socioeconomic status and mental disorders: a longitudinal study of selection and causation during young adulthood. Am J Sociol 1999; 104: 1096-131.

47. Farmer EMZ. Extremity of externalizing behavior and young adult outcomes. J Child Psychol Psyc 1995; 36: 617-32.

48. Kessler RC, Foster CL, Saunders WB, Stang PE. Social consequences of psychiatric disorders, I: educational attainment. Am J Psychiat 1995; 152: 1026-32.

49. McLeod JD, Shanahan MJ. Trajectories of poverty and children's mental health. J Health Soc Behav 1996; 37: 207-20. 
50. Currie J, Stabile M. Child mental health and human capital accumulation: the case of ADHD. J Health Econ 2006; 25: 1094-1118.

51. Currie J, Stabile M. Mental health in childhood and human capital. In: Gruber J, editor: The problems of disadvantaged youth: an economic perspective. Chicago: University of Chicago Press, 2009; 115-48.

52. Mannuzza S, Klein R. Long-term prognosis in attention-deficit/hyperactivity disorder. Child Adol Psych Cl 2000; 9: 711-26.

53. Webbink D, Vujic S, Koning P, Martin NG. The effect of childhood conduct disorder on human capital. Health Econ 2012; 21: 928-45.

54. Rees DI, Sabia JJ, The effect of migraine headache on educational attainment. J Hum Resour 2011; 46: 317-32.

55. Fowler MG, Davenport MG, Garg R. School functioning of US children with asthma. Pediatrics 1992; 90: 939-44.

56. Halterman JS, Montes G, Aligne CA, Kaczorowski JM, Hightower D, Szilagyi PG. School readiness among urban children with asthma. Ambul Pediatr 2001; 14: 2015.

57. Case A, Paxson SC. Early life health and cognitive function in old age. Am Econ Rev 2009; 99: 104-9.

58. Davis-Kean PE. The influence of parent education and family income on child achievement: the indirect role of parental expectations and the home environment. $\mathrm{J}$ Fam Psychol 2005; 19: 294-304.

59. Sewell W, Shah VP. Parents' education and children's educational aspirations and achievements. Am Sociol Rev 1968; 33: 191-209.

60. Ermisch J, Francesconi M. Family matters: impacts of family background on educational attainments. Economica 2001; 68: 137-56. 
61. Newacheck PW, Strickland B, Shonkoff JP, Perrin JM, McPherson M, McManus M, Lauver C, Fox H, Arango P. An epidemiologic profile of children with special health care needs. Pediatrics 1998; 102: 117-23.

62. Lau RR, Quadrel MJ, Hartman KA. Development and change of young adults' preventive health beliefs and behavior: influence for parents and peers. J Health Soc Behav 1990; 31: 240-59.

63. Case A, Fertig A, Paxson C. The lasting impact of childhood health and circumstance. J Health Econ 2005; 24: 365-89.

64. Baker DW, Parker RM, Williams MV, Clark WS, Nurss J. The relationship of patient reading ability self-reported health and use of health services. Am J Public Health 1997; 87: 1027-30.

65. Auld MC, Sidhu N. Schooling, cognitive ability and health. Health Econ 2005; 14: 1019-34.

66. Eberhardt MS, Pamuk ER. The importance of place of residence: examining health in rural and nonrural areas. Am J Public Health 2004; 94: 1682-6.

67. Hartley D. Rural health disparities, population health, and rural culture. Am J Public Health 2004; 94: 1675-8.

68. Falba TA, Sindelar JL. Spousal concordance in health behavior change. Health Serv Res 2008; 43: 96-116.

69. Sutton GC. Assortative marriage for smoking habits. Ann Hum Biol 1980; 7: 44956.

70. Venters MH, Jacobs R Jr, Luepker RV. Spouse concordance of smoking patterns: the Minnesota Heart Survey. Am J Epidemiol 1984; 120: 608-16. 
71. Leonard KE, Das Eiden R. Husband's and wife's drinking: unilateral or bilateral influences among newlyweds in a general population sample. J Stud Alcohol 1999; 60: $130-8$.

72. Macken LC, Yates B, Blancher S. Concordance of risk factors in female spouses of male patients with coronary heart disease. J Cardiopulm Rehabil 2000; 20: 361-8.

73. Fuchs VR. Time preference and health: an exploratory study. In: Fuchs, editor: Economic aspects of health. Chicago: University of Chicago Press for the National Bureau of Economic Research, 1982; 93-120.

74. Farrell P, Fuchs VR. Schooling and health: the cigarette connection. J Health Econ 1982; 1:217-30.

75. Van der Pol M. Health, education and time preference. Health Econ 2011; 20: 91729.

76. Ippolito R. Education versus savings as explanations for better health: evidence from the health and retirement survey. George Mason Law \& Economics Research Paper No. 03-04. Arlington: George Mason University School of Law, 2003.

77. Shrier I, Platt RW. Reducing bias through directed acyclic graphs. BMC Med Res Methodol 2008; 8: 70.

78. D’Onofrio BM, Class QA, Rickert ME, Sujan AC, Larsson H, Kuja-Halkola R, Sjölander A, Almqvist C, Lichtenstein P, Oberg AS. Translational epidemiologic approaches to understanding the consequences of early-life exposures. Behav Genet 2016; 46: 315-28.

79. Schlotter M, Schwerdt G, Woessmann L. Econometric methods for causal evaluation of education policies and practices: a non-technical guide. Educ Econ 2011; 19: 109-37.

80. Newhouse JP, McClellan M. Econometrics in outcomes research: the use of instrumental variables. Annu Rev Public Health 1998; 19: 17-34. 
81. Greenland S. An introduction to instrumental variables for epidemiologists. Int J Epidemiol 2000; 29: 722-9.

82. Rassen JA, Brookhart MA, Glynn RJ, Mittleman MA, Schneeweiss S. Instrumental variables I: instrumental variables exploit natural variation in nonexperimental data to estimate causal relationships. J Clin Epidemiol 2009; 62: 1226-32.

83. Lawlor DA, Harbord RM, Sterne JAC, Timpson N, Smith GD. Mendelian randomization: using genes as instruments for making causal inferences in epidemiology. Stat Med 2008; 27: 1133-63.

84. Angrist JD, Imbens GW, Rubin DB. Identification of causal effects using instrumental variables. J Am Stat Assoc 1996; 91: 444-55.

85. Angrist JD, Pischke JS. The credibility revolution in empirical economics: how better research design is taking the con out of econometrics. J Econ Perspect 2010; 24: 3-30.

86. Deaton A. Instruments, randomization, and learning about development. J Econ Lit 2010; 48: 424-55.

87. Oreopoulos P, Salvanes KG. Priceless: the nonpecuniary benefits of schooling. J Econ Perspect 2011; 25: 159-84.

88. Listl S, Jürges H, Watt RG. Causal inference from observational data. Community Dent Oral Epidemiol 2016; 44: 409-15.

89. Angrist JD, Pischke JS. Mostly harmless econometrics. An empiricist's companion. Princeton and Oxford: Princeton University Press, 2009; 113-218.

90. Martens EP, Pestman WR, de Boer A, Belitser S, Klungel OH. Instrumental variables. Application and limitations. Epidemiology 2006; 17: 260-7.

91. Mazumder B. The effects of education on health and mortality. Nord Econ Policy Rev 2012; 1: 261-303. 
92. Gathmann C, Jürges H, Reinhold S. Compulsory schooling reforms, education and mortality in twentieth century Europe. Soc Sci Med 2015; 127: 74-82.

93. Lleras-Muney A. The relationship between education and adult mortality in the United States. Rev Econ Stud 2005; 72: 189-221.

94. Clark D, Royer H. The effect of education on adult mortality and health: evidence from Britain. Am Econ Rev 2013; 103: 2087-120.

95. Van Kippersluis H, O’Donnell O, Van Doorslaer E. Long-run returns to education. Does schooling lead to an extended old age? J Hum Resour 2011; 46: 695-721.

96. Fletcher JM. New evidence of the effects of education on health in the US: compulsory schooling laws revisited. Soc Sci Med 2015; 127: 101-7.

97. Braakmann N. The causal relationship between education, health and health related behaviour: evidence from a natural experiment in England. J Health Econ 2011; 30: 753-63.

98. Lager ACJ, Torssander J. Causal effect of education on mortality in a quasiexperiment on 1.2 million Swedes. Proc Natl Acad Sci USA 2013; 109: 8461-66.

99. Arendt JN. Does education cause better health? A panel analysis using school reforms for identification. Econ Educ Rev 2005; 24: 149-60.

100. Kemptner D, Jürges H, Reinhold S. Changes in compulsory schooling and the causal effect of education on health: evidence from Germany. J Health Econ 2011; 30: 340-54.

101. Grytten J, Skau I, Sørensen RJ. Educated mothers, healthy infants. The impact of a school reform on the birth weight of Norwegian infants 1967-2005. Soc Sci Med 2014; 105: 84-92.

102. Meghir C, Palme M. Educational reform, ability, and family background. Am Econ Rev 2005; 95: 414-24. 
103. Lager ACJ, Torssander J. Causal effect of education on mortality in a quasiexperiment on 1.2 million Swedes. P Natl Acad Sci USA 2012; 109: 8461-66.

104. Arendt JN. In sickness and in health - till education do us part: education effects on hospitalization. Econ Educ Rev 2007: 27: 161-72.

105. Jones AM. Identification of treatment effects in health economics. Health Econ 2007; 16: 1127-31.

106. Staiger D, Stock JH. Instrumental variables regression with weak instruments. Econometrica 1997; 65: 557-86.

107. Lindeboom M, Llena-Nozal A, van der Klaauw. Parental education and child health: evidence from a schooling reform. J Health Econ 2009; 28: 109-31.

108. Rehkopf DH, Glymour MM, Osypuk TL. The consistency assumption for causal inference in social epidemiology: when a rose is not a rose. Curr Epidemiol Rep 2016; 3: 63-71.

109. Fujiwara T, Kawachi I. Is education causally related to better health? A twin fixedeffect study in the USA. Int J Epidemiol 2009; 38: 1310-22.

110. Madsen M, Andersen AMN, Christensen K, Andersen PK, Osler M. Does educational status impact adult mortality in Denmark? A twin approach. Am J Epidemiol 2010; 172: 225-34.

111. Lundborg P. The health returns to education - what can we learn from twins? Tinbergen Institute Discussion Paper No. TI 08-027/3. Rotterdam: Tinbergen Institute, 2008. Available at: http://papers.ssrn.com/sol3/papers.cfm?abstract id=1113685 (February 16, 2017).

112. Madsen M, Osler M. Commentary: Strengths and limitations of the discordant twinpair design in social epidemiology. Where do we go from here? Int $\mathbf{J}$ Epidemiol 2009; 38: 1322-3. 
113. D’Onofrio BM, Lahey BB, Turkheimer E, Lichtenstein P. Critical need for familybased, quasi-experimental designs in integrating genetic and social science research. Am J Public Health 2013; 103 (suppl 1): S46-S55.

114. Lahey BB, D’Onofrio BM. All in the family: comparing siblings to test causal hypotheses regarding environmental influences on behavior. Curr Dir Psychol Sci 2010; 19: 319-23.

115. Rutter M. Proceedings from observed correlation to causal inference. Perspect Psychol Sci 2007; 2: 377-95.

116. Frisell T, Öberg S, Kuja-Halkola R, Sjölander A. Sibling comparison designs. Bias from non-shared confounders and measurement error. Epidemiology 2012; 23: 713 20.

117. Donovan SJ, Susser E. Commentary: advent for siblings designs. Int J Epidemiol 2011; 40: 345-9.

118. Søndergaard G, Mortensen LH, Andersen AMN, Andersen PK, Dalton SO, Madsen M, Osler M. Does shared family background influence the impact of educational differences on early mortality? Am J Epidemiol 2012; 176: 675-83.

119. Cook CJ, Fletcher JM. Can education rescue genetic liability for cognitive decline? Soc Sci Med 2015; 127: 159-70.

120. Keys KM, Smith GD, Susser E. On siblings designs. Epidemiology 2013; 24: 4734.

121. Bound J, Solon G. Double trouble: on the value of twins-based estimation of the return to schooling. Econ Educ Rev 1999; 18: 169-82.

122. Behrman JR, Rosenzweig MR, Taubman P. Endowments and the allocation of schooling in the family and in the marriage market: the twins experiment. J Polit Econ 1994; 102: 1131-74. 
123. Kamin LJ. Transfusion syndrome and the heritability of IQ. Ann Hum Genet 1978; 42: 161-71.

124. James WH. The IQ advantage of the heavier twin. Br J Psychol 1982; 73: 513-7.

125. Lee DS, Lemieux T. Regression discontinuity designs in economics. J Econ Lit 2010; 48: 281-355.

126. Zuckerman IH, Lee E, Wutoh AK, Xue Z, Stuart B. Application of regressiondiscontinuity analysis in pharmaceutical health services research. Health Serv Res 2006; 41: 550-63.

127. Linden A, Adams JL, Roberts N. Evaluating disease management programme effectiveness: an introduction to the regression discontinuity design. J Eval Clin Pract 2006; 12: 124-31.

128. McCrary J, Royer H. The effect of female education on fertility and infant health: evidence from school entry policies using exact date of birth. Am Econ Rev 2011; 101: 158-95.

129. Albouy V, Lequien L. Does compulsory education lower mortality? J Health Econ 2009; 28: 155-68.

130. Angrist JD, Pischke JS. Mostly harmless econometrics. An empiricist's companion. Princeton: Princeton University Press, 2009; 251-67.

131. Zhong H. Does a college education cause better health and health behaviours? Appl Econ 2015; 47: 639-53.

132. Cameron AC, Miller DL. A practioner's guide to cluster-robust inference. J Hum Resour 2015; 50: 317-72.

133. Angrist JD, Pischke JS. Mostly harmless econometrics. An empiricist's companion. Princeton: Princeton University Press, 2009; 227-33. 
134. Oreopoulos P. Estimating average and local average treatment effects of education when compulsory schooling laws really matter. Am Econ Rev 2006; 96: 152-75.

135. Helliwell JF, Putnam RD. Education and social capital. NBER Working Paper 7121. Cambridge, MA: National Bureau of Economic Research, 1999. Available at: http://www.nber.org/papers/w7121 (February 16, 2017).

136. Eibner C, Evans WN. Relative deprivation, poor health habits and mortality. J Hum Resour 2005; 40: 591-620.

137. Gerdtham U-G. Johannesson M. Absolute income, relative income, income inequality, and mortality. J Hum Resour 2004; 39: 228-47.

138. Cattell V. Poor people, poor places, and poor health: the mediating role of social networks and social capital. Soc Sci Med 2001; 52: 1501-16.

139. Kaplan BH, Cassel JC, Gore S. Social support and health. Med Care 1977; 15: 4758.

140. Wilkinson RG, Pickett KE. Income inequality and population health: a review and explanation of the evidence. Soc Sci Med 2006; 62: 1768-84.

141. Kawachi I, Subramanian AV, Almeida-Filho N. A glossary for health inequalities. J Epidemiol Community Health 2002; 56: 647-52.

142. Singh-Manoux A, Adler NE, Marmot MG. Subjective social status: its determinants and its association with measures of ill-health in the Whitehall II study. Soc Sci Med 2003; 56: 1321-33.

143. Wilkinson RG. Socioeconomic determinants of health. Health inequalities: relative or absolute material. BMJ 1997; 314: 591-9.

144. Wilkinson RG. Unhealthy societies. The afflictions of inequality. London: Routledge, 1996. 
145. Lynch JW, Smith GD, Kaplan GA, House JS. Income inequality and mortality: importance to health of individual income, psychosocial environment, or material conditions. BMJ 2000; 320: 1200-4.

146. Muller A. Education, income inequality, and mortality: a multiple regression analysis. BMJ 2002; 324: 1-4.

147. Marmot M. The influence of income on health: views of an epidemiologist. Health Affairs 2002; 21: 31-46. 


\section{Captions:}

Fig. 1. Percentage of the population with tertiary education among European countries during the period 1960-2005

Fig. 2. The relationship between different types of third variables and education and dental health outcome

Fig. 3. Estimation of causal effect by the use of instrumental variable

Fig. 4. Regression discontinuity design 


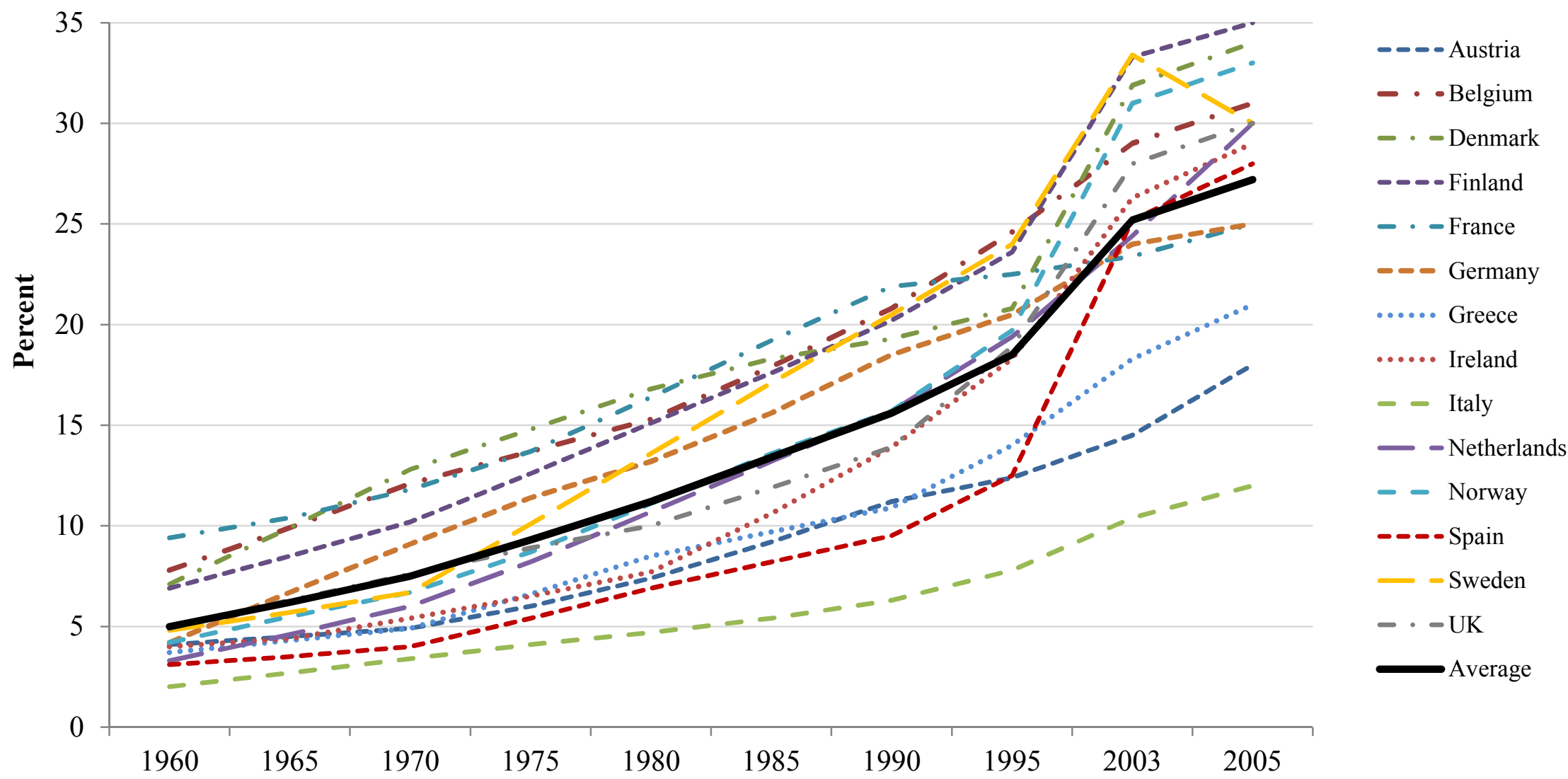

Fig. 1. Percentage of the population with tertiary education among European countries during the period 1960-2005. 


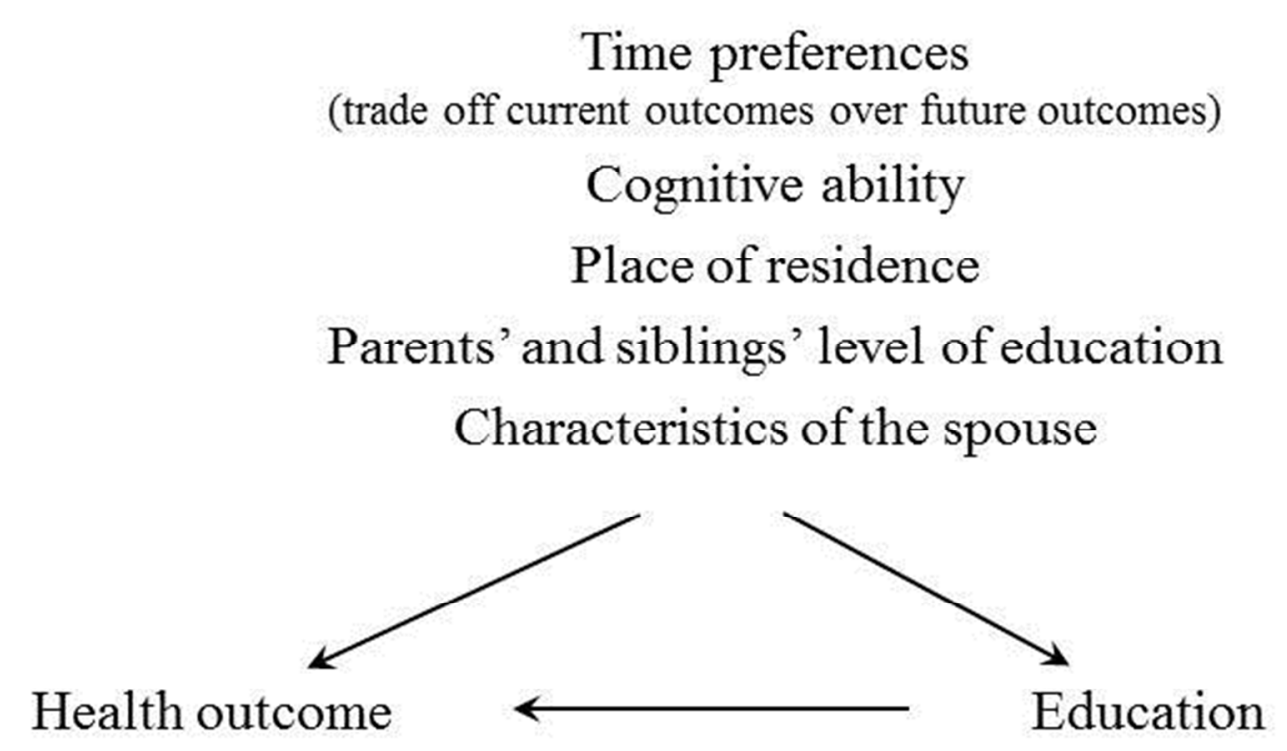

Fig. 2. The relationship between different types of third variables and education and dental health outcome 
Health outcome

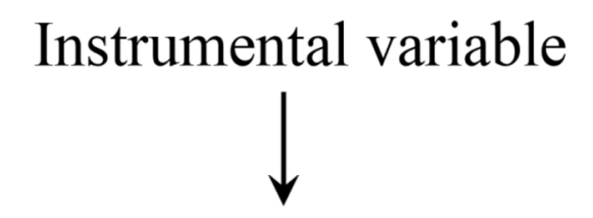

Treatment variable + error term (schooling)

Fig. 3. Estimation of causal effect by the use of instrumental variable 


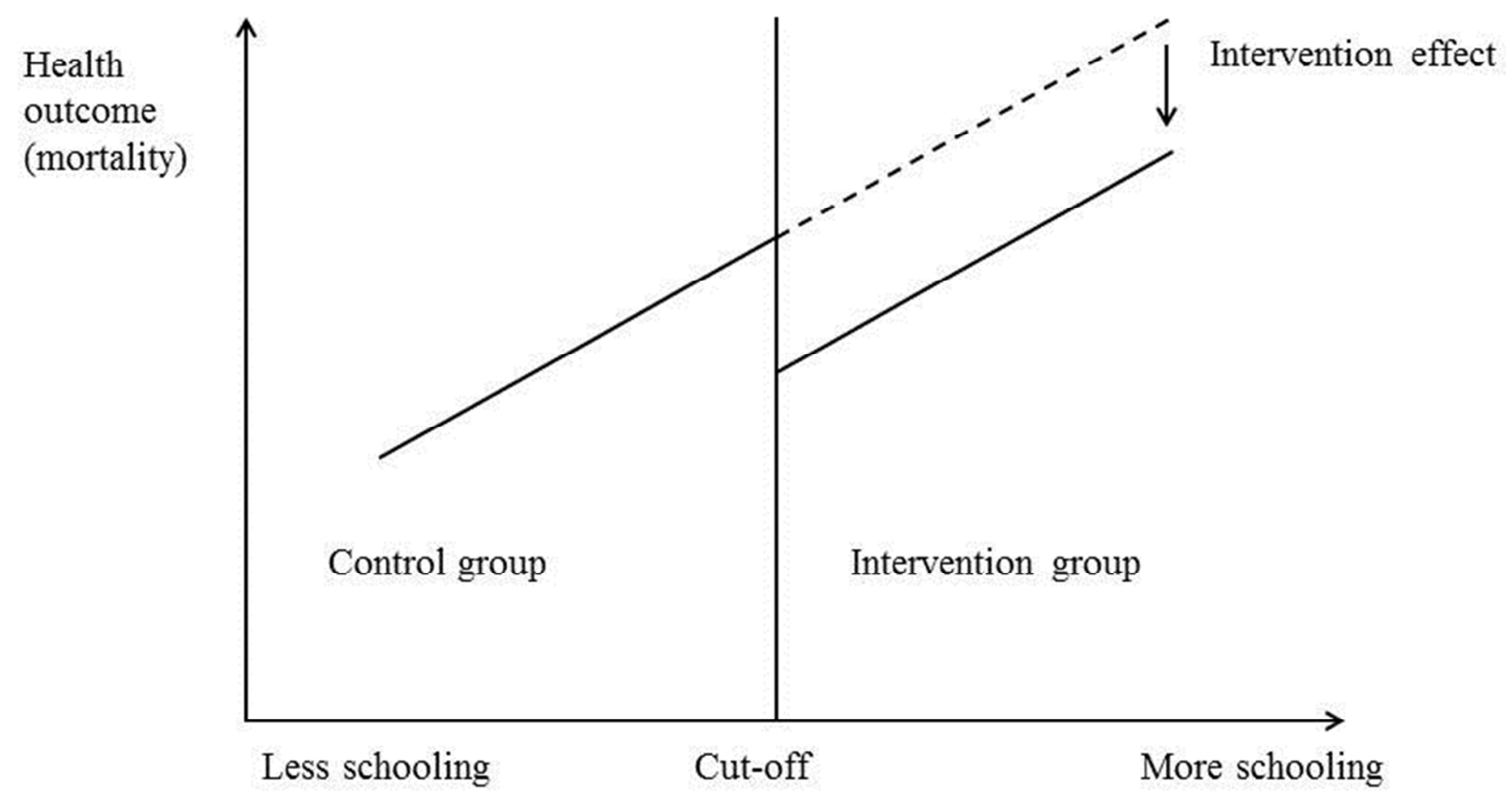

Fig. 4. Regression discontinuity design 